\title{
DEGRADATION OF SINTERED CARBIDES IN DIFFERENT CORROSIVE ENVIRONMENTS
}

\author{
David Bricín, Jan Pomahač \& Antonín Kříž
}
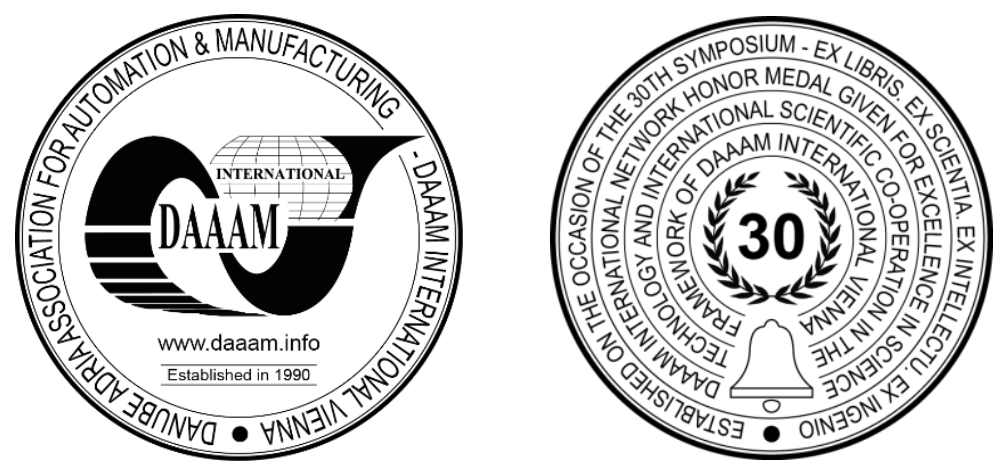

This Publication has to be referred to as Bricin, D[avid]; Pomahac, J[an] \& Kriz, A[ntonin] (2019). Degradation of Sintered Carbides in Different Corrosive Environments, Proceedings of the 30th DAAAM International Symposium, pp.0646-0653, B. Katalinic (Ed.), Published by DAAAM International, ISBN 978-3-902734-22-8, ISSN 1726-9679, Vienna, Austria

DOI: $10.2507 / 30$ th.daaam.proceedings.089

\begin{abstract}
The aim of the study was to determine the corrosion resistance of different types of sintered carbides in alkaline and acidic environments. The degradation environment for sintered carbides was chosen so that its $\mathrm{pH}$ corresponds to those with which these carbides normally come into contact during their use as machining tools or drilling tools used in the extractive industry. The experimental material was selected from sintered carbides based on WC-Co and WC-Ni. The materials chosen differed in the contents of the binder and the grain size of the WC. Three alkaline media and three acidic media were selected as the degradation media, with $\mathrm{pH}$ values of $0,2,7$ and 12 , in which the rate at which dissolution of the cemented carbide was observed. In addition to determining the solubility rate of the binder, the corrosion resistance of sintered carbides was evaluated using a potentiostat and the binder fraction in the solvents using atomic absorption spectrometry. The experiments showed, for example, that the highest amount of binder in sintered carbides with a cobalt binder was dissolved in solutions with high sulphuric acid content. In contrast with the solution of $\mathrm{NaOH}$ or $\mathrm{CH} 3 \mathrm{COOH}$.
\end{abstract}

Keywords: Sintered Carbide; Corrosion resistance; the rate of degradation; WC-Co; WC-Ni;

\section{Introduction}

Sintered carbides are a composite material which consists of two basic phases. These phases are tungsten carbide grains and cobalt as a binder which makes a skeleton structure surrounding the grains of tungsten carbide. These two phases are alpha phase (WC) and beta phase (Co). Sintered carbides may also consist of other types of metallic binders such as iron, nickel or metallic solutions which have good wettability of the alpha phase. Apart from alpha or beta phases, they may also contain other types of carbides such as $\mathrm{TiC}, \mathrm{TaC}$ or $\mathrm{NbC}$ which is known as the gamma phase. Thanks to a combination of different amounts and types of beta phase, different grain sizes in the alpha phase and the addition of gamma phase it is possible to change the mechanical properties, the physical properties and the chemical properties of the sintered carbides making it possible to adapt them for applications and environments where products such as nozzles or cutting tools will be used. Despite the adaptation of the WC-Co structure to these applications, this material will be degraded either by mechanical stress, for example by abrasion during machining, or by its interaction with solutions that may contain soils or acid solutions when they are used in the mining industry.[6], [11], [14] This article deals with one type of degradation process of sintered carbides which is caused by the chemical activity of the environment which affects the corrosion resistance of sintered carbides. One of the main objectives of the experiment was to verify the corrosion resistance of the sintered carbides during their long exposure in selected corrosive environments. 
Research has shown [1], [2], [3], [4], [5], [6], [8], [9], [10], [12], [14] that corrosion resistance of cemented carbides is primarily dependent on the chemical purity of the binder and its chemical composition. Corrosion of cemented carbides occurs because tungsten carbide grains and the binder form a galvanic cell where the environment creates an electrolyte. The binder in this electrochemical circuit then forms an anode that dissolves into the environment and the tungsten carbides form a cathode where reduction of hydrogen or oxygen occurs. As a result, there is a local increase in $\mathrm{pH}$ in the surroundings of the WC grains, which in turn leads to their gradual dissolution. However, before they are completely dissolved, they are released into the surrounding environment due to the loss of binder surrounding them. The corrosion resistance of sintered carbides also depends on the size of the tungsten carbide grains and the amount of binder. It was observed that if the tungsten carbide grain size was reduced, then the polarization resistance (Rp) increased. The same phenomenon was also observed for the binder content. If the binder content was reduced, then the polarization resistance (Rp) again increased. This is because when reducing the grain size of the carbide, the area from which carbon and tungsten diffuse into the binder increases during sintering. By reducing the proportion of binder in the cemented carbide structure, the free length - the distance between the carbide grains - is reduced. As a result, a higher binder volume is saturated by tungsten and carbon. The diffusing elements during the sintering stabilize the high-temperature phase of the binder, which is more stable to corrosion, corresponding to the increase in polarization resistance ( $\mathrm{Rp}$ ). The corrosive environment is one of the last factors that influence the corrosion behaviour of cemented carbides. It has been found that cobalt binders and nickel binders resist very well in environments with a $\mathrm{pH}$ higher than 6 . However, for $\mathrm{pH}$ environments below 6 , the use of cobalt binders is disadvantageous because of their lower polarization resistance. Therefore, it is not advantageous to use sintered carbides with a cobalt binder for woodworking where the $\mathrm{pH}$ of wood moves from a value of 3 to a value of $8 .[12]$

In the experiment described in this paper, we studied the rate at which corrosive degradation of various types of cemented carbides occurs in various corrosive environments. In the experiment, the weight loss and the amount of dissolved binder in the degradation media used were measured. Degradation environments were predominantly chosen with regard to industrial applications of cemented carbides and with regard to their recycling methods.

\section{Experimental materials and experimental methods}

Four types of cemented carbides were selected as the experimental material. They differed in their chemical compositions and tungsten carbide grain size, see Table 1 and Figure 1. This selection of materials allowed evaluation of the influence of the binder chemical composition and the tungsten carbide particle size on the rate of the degradation processes in various corrosive environments. The chemical composition of the binder and the grain size of the carbides was analysed using a Tescan Vega 3 electron scanning microscope and compared with the data from the material supplier's catalogue. It was found that the data from the analysis of the delivered materials corresponded to the data from the supplier's catalogue.
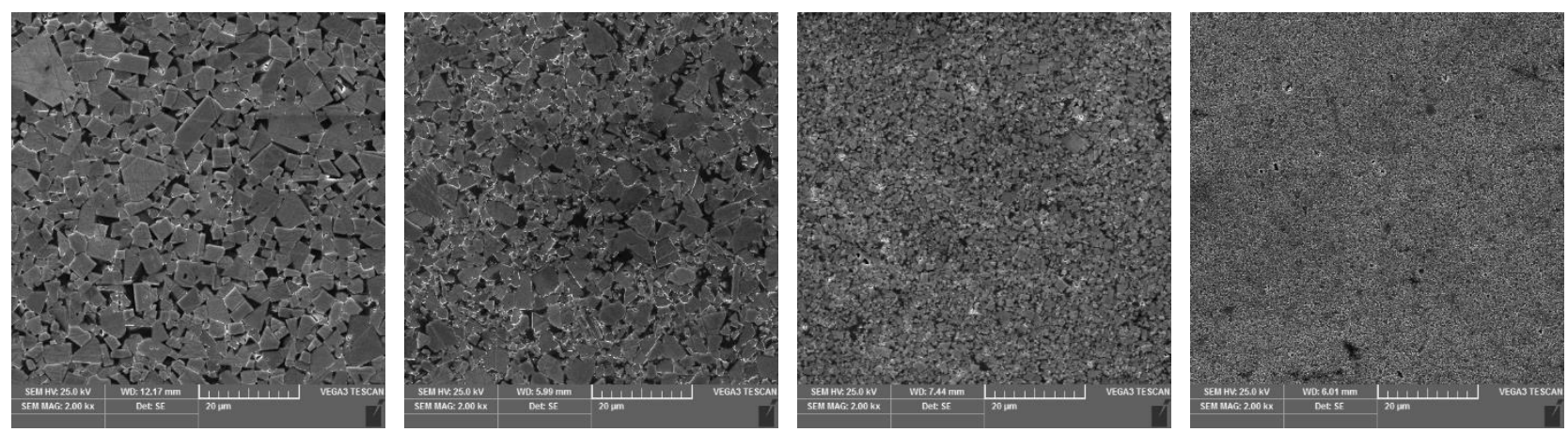

Fig. 1. Structure of the experimental material. The structure was induced by chemical etching with Murakami etchant. The first image from the left shows the structure of sample A. The second image from the left shows the structure of sample B. The third image from the left shows the structure of sample C. The fourth image from the left shows the structure of sample 4

\begin{tabular}{|c|c|c|c|}
\hline Sample ID & Grain Size of WC & Type of Binder & $\begin{array}{c}\text { Amount of Binder } \\
\text { Wt. \% }\end{array}$ \\
\hline Sample A & $3-6 \mu \mathrm{m}$ & $\mathrm{Co}$ & $8 \pm 0.2$ \\
\hline Sample B & $1-1.3 \mu \mathrm{m}$ & $\mathrm{Ni}$ & $12 \pm 0.1$ \\
\hline Sample C & $3-6 \mu \mathrm{m}$ & $\mathrm{Co}-\mathrm{Ni}-\mathrm{Cr}$ & $10 \pm 0.5$ \\
\hline Sample D & $0.3-0.5 \mu \mathrm{m}$ & $\mathrm{Co}$ & $8 \pm 0.2$ \\
\hline
\end{tabular}

Table 1. Properties of the experimental materials 
A total of six aqueous solutions of acids and bases with a concentration of 20 wt. \% were used as corrosive environments. Three of them were basic solutions and three were acidic solutions, see Table 2 . The chemical composition of some solutions was chosen to match the processes used to recycle cemented carbides. Others were chosen to match their use as woodworking tools, where the intensive dissolution of binder occurs during the cutting process. Murakami etchant is commonly used to evaluate the structural composition of cemented carbides. For this research it was chosen as one of the comparative degradation environments. The aim was to compare how the solubility of cemented carbides varies in this environment and in the solutions used to recycle them, or the solutions which come into contact with their surfaces during their working life.

\begin{tabular}{|c|c|c|c|}
\hline Type of Environment & pH Factor & chemical formula & Typical use (occurrence) of the environment \\
\hline Acidic solution & 0 & $\mathrm{H}_{2} \mathrm{SO}_{4}$ & Recycling cemented carbides \\
\hline Acidic solution & $2-3$ & $\mathrm{CH}_{3} \mathrm{COOH}$ & Wood cutting using cemented carbides \\
\hline Acidic solution & 0 & $3 \mathrm{HCl}+\mathrm{HNO}{ }_{3}$ & Recycling cemented carbides \\
\hline Alkaline solution & 12 & $\mathrm{NaOH}$ & Recycling cemented carbides \\
\hline Alkaline solution & 12 & $\mathrm{KOH}$ & Unspecified \\
\hline Alkaline solution & $8-9$ & $\mathrm{~K}_{3} \mathrm{Fe}(\mathrm{CN})_{6}+\mathrm{KOH}$ & Metallographic analysis of cemented carbides \\
\hline
\end{tabular}

Table 2. Chemical environments which were used as corrosive solutions

The weight loss of the sintered carbide samples was evaluated using Radwag AS 220 / C / 2 precision metallographic scales, which allow measurement with a deviation of $0.1 \mathrm{mg}$. This was measured at regular intervals every 24 hours for 32 days. The resulting data allowed us to determine the degradation rate of the structure of the sintered carbides in different types of corrosive environments. This measurement was supplemented by analysis of the surface condition of the samples by metallographic analysis and analysis of the amount of dissolved binder in various degradation media. Atomic absorption spectroscopy was used to measure the volume of the dissolved binder in the corrosive environments.

\section{Results of experiments and discussion}

Figure 2 summarizes the total weight loss of samples after 32 days of exposure to the corrosive environments. It is clear from the graph that the most intense degradation of samples takes place in sulphuric acid and potassium ferricyanide mixed with potassium hydroxide.

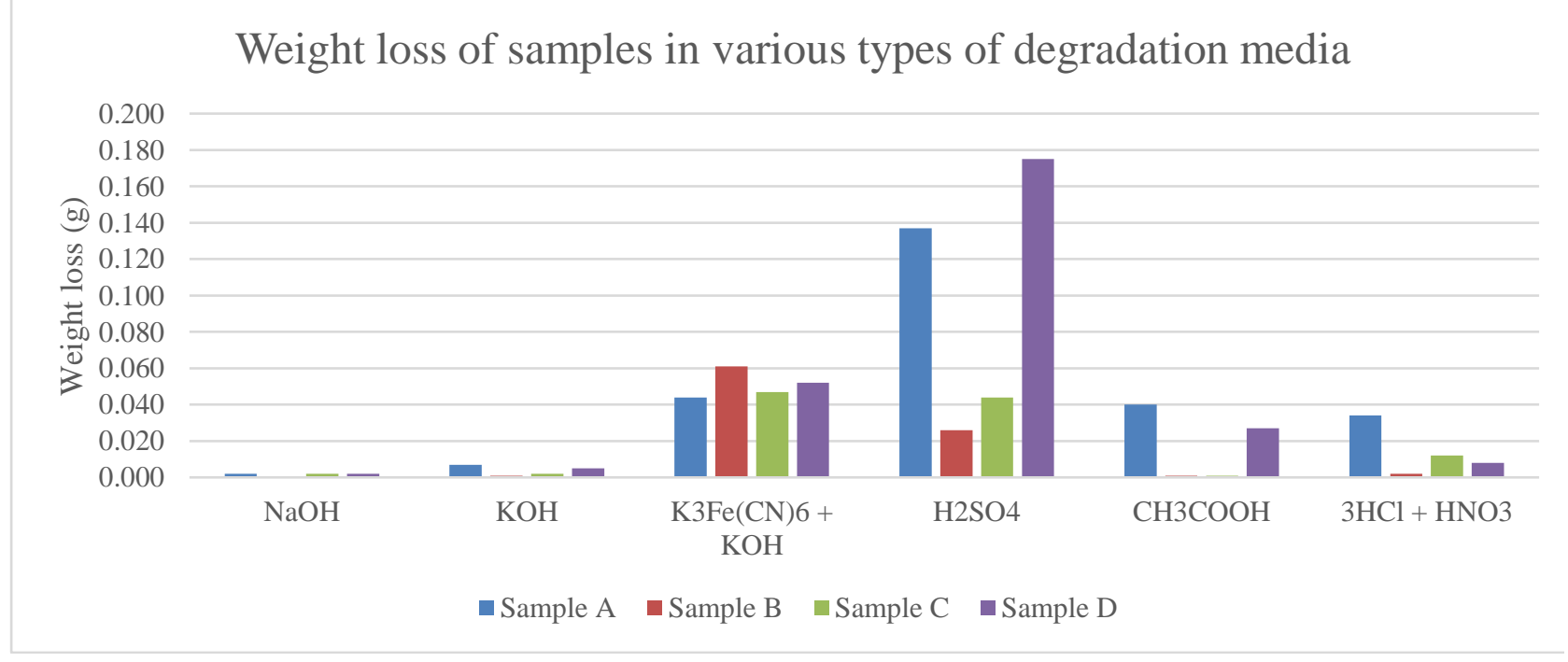

Fig. 2. Total weight loss in the analysed samples after 32 days in different degradation media

The data shown in Figure 2 confirms the theory above. For sample B, where the nickel binder was better resistant to acidic environments, lower weight loss was measured. The weight loss of the sample with nickel binder in sulphuric acid was about $57 \%$ lower than in the potassium ferricyanide solution. In addition, the effect of tungsten carbide grain size on the rate of degradation of cemented carbides in various corrosive environments was demonstrated. In addition, the effect of grain size on the rate of degradation of cemented carbides in various corrosive environments was demonstrated. When comparing the results for sample A and sample B, it is evident that almost all types of degradation media cause more intensive degradation of the surface of sample A which had coarser grains of tungsten carbide than sample D. Different behaviour from the theory was observed for an aqueous solution of sulphuric acid and for a solution of potassium ferricyanide. It is observed that prolonged exposure of samples to these environments results in more intense degradation 
of the sample surface in samples with finer tungsten carbide grain sizes than coarser ones. This can be explained by the fact that with the same binder volume and different tungsten carbide grain size, the binder occupies a larger contact surface with the corrosive environment if samples contain smaller tungsten carbide grains. As a result, the surface of the sample is formed by a higher number of corrosion cells, which cause a more intensive degradation of the sample surface than for samples containing coarser tungsten carbide grains where the contact surface with the corrosive environment is smaller. In addition, these corrosive environments are likely to have higher electrochemical potentials than other environments used in the experiment.

In addition to the total weight loss, the samples were evaluated for degradation, i.e. weight loss, over 32 days, when samples were weighed every 24 hours. Below are the results for two environments where sample degradation was most intense. This is a solution of potassium ferricyanide (Fig. 3) and sulphuric acid solution (Fig. 4).

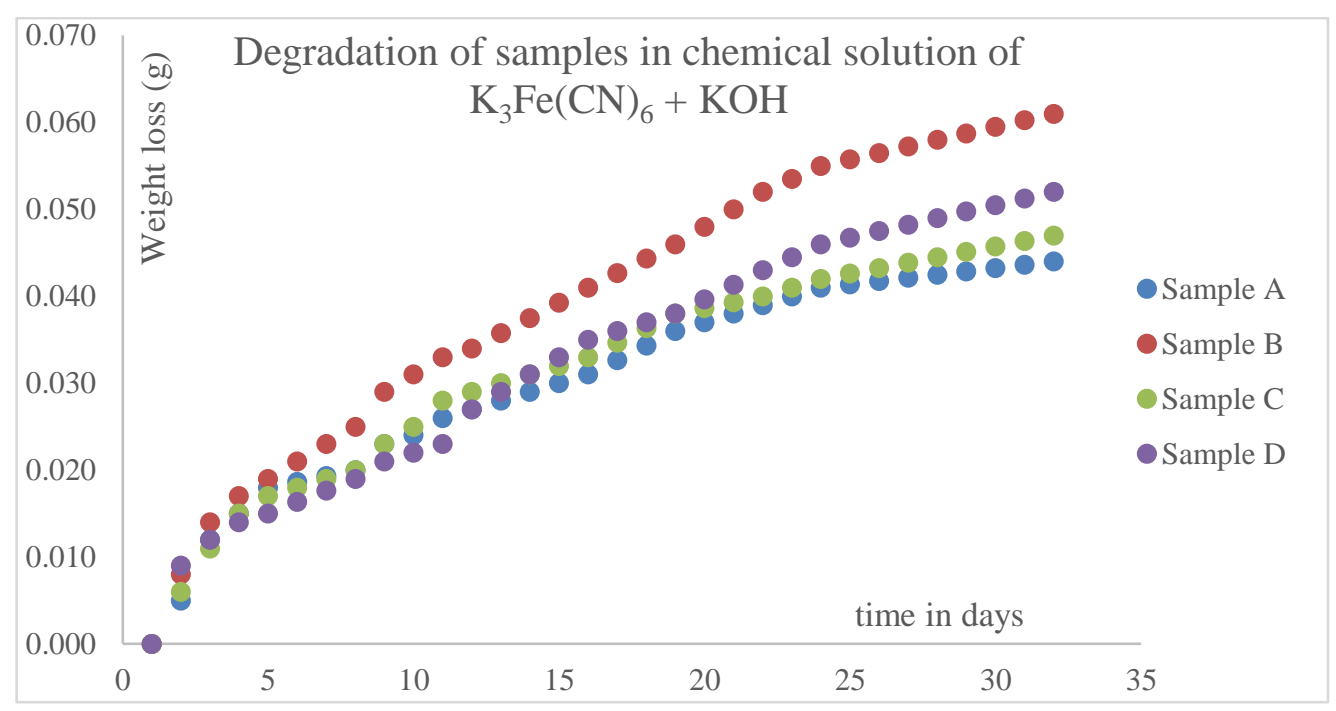

Fig. 3. Change in volume of dissolved material in alkaline corrosive environments over time

From Figure 3, it can be seen that in alkaline environments the degradation rate in the first days of the experiment was similar for all samples. After about five days, a higher degradation rate for sample B was observed which contained a nickel binder, which resulted in a decrease in the measured weight loss. This fact was associated with the formation of passivating oxide layers that formed on the contact surface of the samples in degradation environments. These layers have in some cases completely stopped the degradation of the cemented carbide during the first days of their interaction, see Figure 5.

The process of sample degradation in the potassium ferrocyanide solution could then be described by the equations below, (equations 1-3).[3], [7], [10] These equations describe the interaction of elements of the binder with elements of the degradation media. Equation 1 describes the interaction of Co, which is a part of the binder of samples A, C, and D. Equation 2 describes the interaction of $\mathrm{Ni}$ which is part of the binder in sample B. Equation 3 describes the interaction of chromium, which is part of the binder in sample $\mathrm{C}$.

$$
\begin{aligned}
& 2 \mathrm{OH}^{-}+\mathrm{Co}^{0}+2 \mathrm{~K}^{+} \rightarrow \mathrm{Co}(\mathrm{OH})_{2}+2 \mathrm{~K} \\
& 2 \mathrm{OH}^{-}+\mathrm{Ni}^{0}+2 \mathrm{~K}^{+} \rightarrow \mathrm{Ni}(\mathrm{OH})_{2}+2 \mathrm{~K} \\
& 2 \mathrm{OH}^{-}+\mathrm{Cr}^{0}+2 \mathrm{~K}^{+} \rightarrow \mathrm{Cr}(\mathrm{OH})_{2}+3 \mathrm{~K}
\end{aligned}
$$

Passivation layers did not form in the sulphuric acid environment, and so the degradation of the material was linear until the end of the experiment for all samples, see Fig. 4. The process of sample degradation in sulphuric acid solution can then be described by equations (4), (5) and (6). [3], [7], [10] These equations describe the interaction of elements of the binder with elements of the degradation media. Equation 4 describes the interaction of Co, which is a part of the binder of samples A, C, and D. Equation 5 describes the interaction of $\mathrm{Ni}$ which is part of the binder of sample B. Equation 6 describes the interaction of chromium, which is part of the binder of sample C.

$$
\begin{aligned}
& \mathrm{SO}_{4}^{-}+\mathrm{Co}^{0}+2 \mathrm{H}^{+} \rightarrow \mathrm{CoSO}_{4}+\mathrm{H}_{2} \\
& \mathrm{SO}_{4}^{-}+\mathrm{Ni}^{0}+2 \mathrm{H}^{+} \rightarrow \mathrm{NiSO}_{4}+\mathrm{H}_{2}
\end{aligned}
$$




$$
3 \mathrm{SO}_{4}^{-}+2 \mathrm{Cr}^{0}+6 \mathrm{H}^{+} \rightarrow \mathrm{Cr}_{2}\left(\mathrm{SO}_{4}\right)_{3}+3 \mathrm{H}_{2}
$$

From Figure 4, it can be seen that the degradation of the samples was constant over time in the sulphuric acid environment. In the first 5 days of measurement, sample A showed a higher degradation rate than sample D which had finer tungsten carbide grains. During this period, the weight loss corresponded to the theoretical assumptions. However, after this time, there was more intensive degradation of sample D, which has a finer tungsten carbide grain structure.

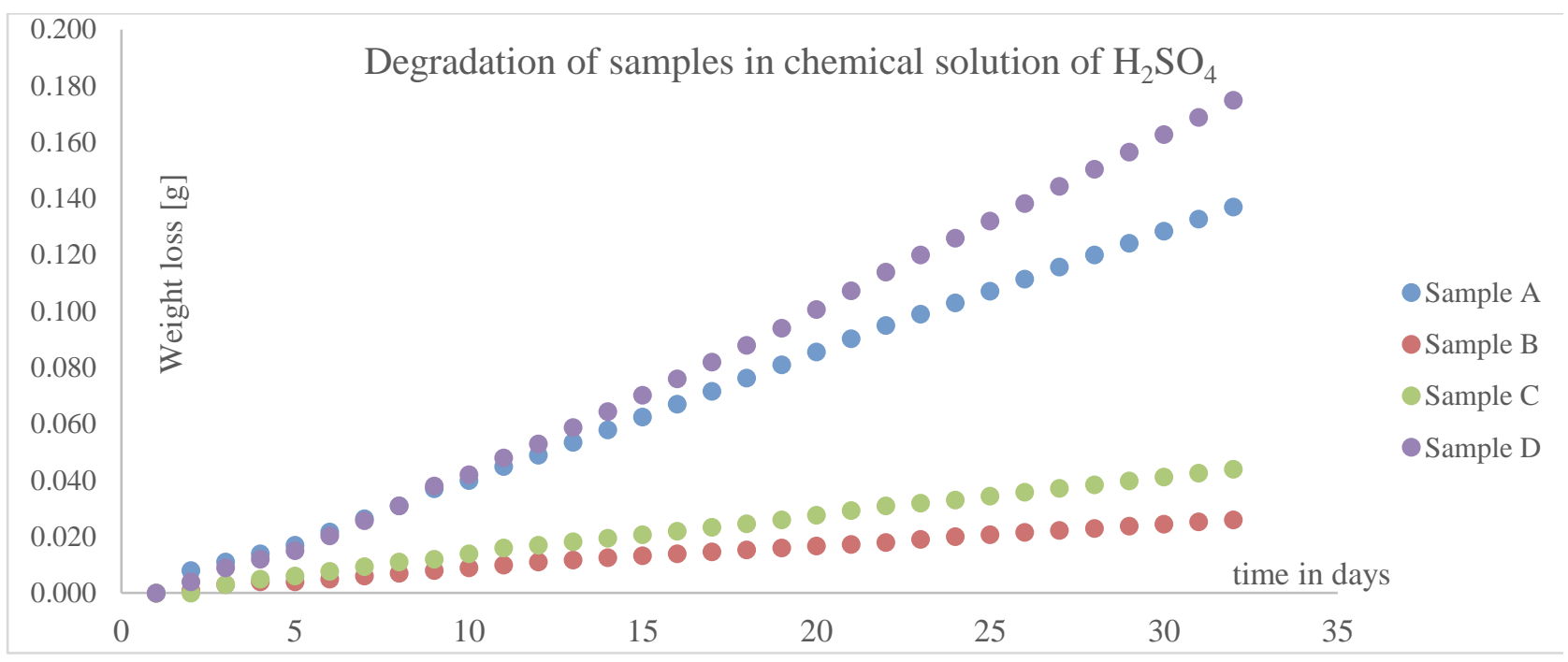

Fig. 4. Change in volume of dissolved material in acidic corrosive environments over time

Again, this is probably associated with the structure of the samples. During long-term exposure of samples in a corrosive environment, particles of tungsten carbide grains are gradually released. This occurs because of the dissolution of the binder that passes into the surrounding degrading environment. Upon release, the grains of WC go into the degradation media as solid particles and reveal material which was behind them. This revealed material is the binder which dissolved by the degradation media and creates a solution with it. Due to this process, the number of corrosion cells that affect the rate at which the corrosion rate proceeds varies at the interface of the sample and the degradation medium. For finegrained material, the number of these cells is higher than in the coarse-grained material, and so the fine-grained sample $\mathrm{D}$ was more degraded than sample $\mathrm{A}$ as time passed. The lowest degradation rate was found for sample $\mathrm{B}$, the least resistant to potassium ferricyanide solution.

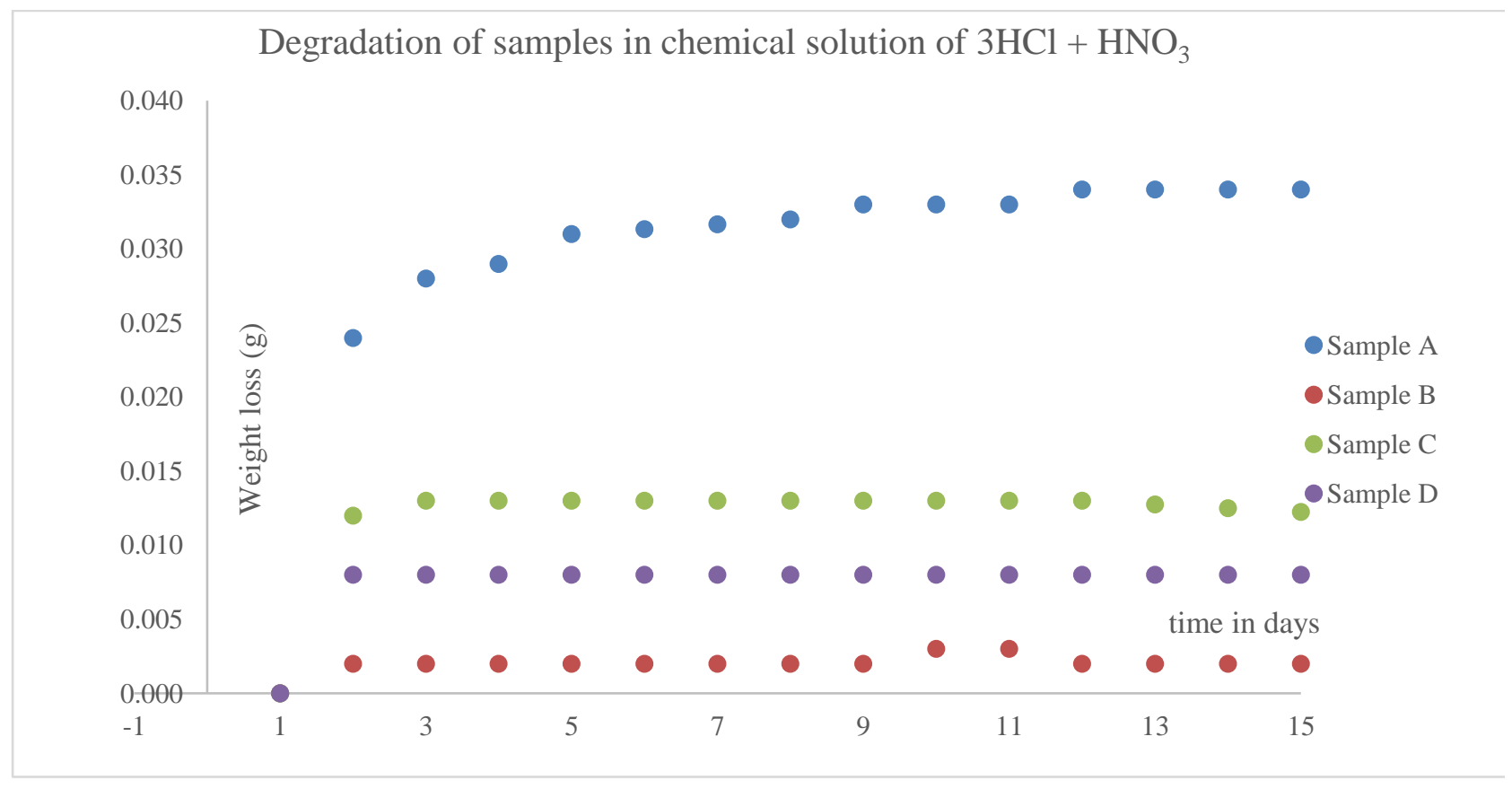

Fig. 5. Change in volume of dissolved material in acidic corrosive environments over time 
The degradation of sintered samples was also reflected in a change in the hardness of the surface that was in contact with corrosive environments. Figures 6 and 7 show the change in hardness of the samples in the environments where their greatest weight loss was observed. Figure 6 shows the change in hardness of samples that were exposed to the alkaline solution of potassium ferricyanide. Figure 7 shows the change in hardness of samples that were exposed to the solution of sulphuric acid.

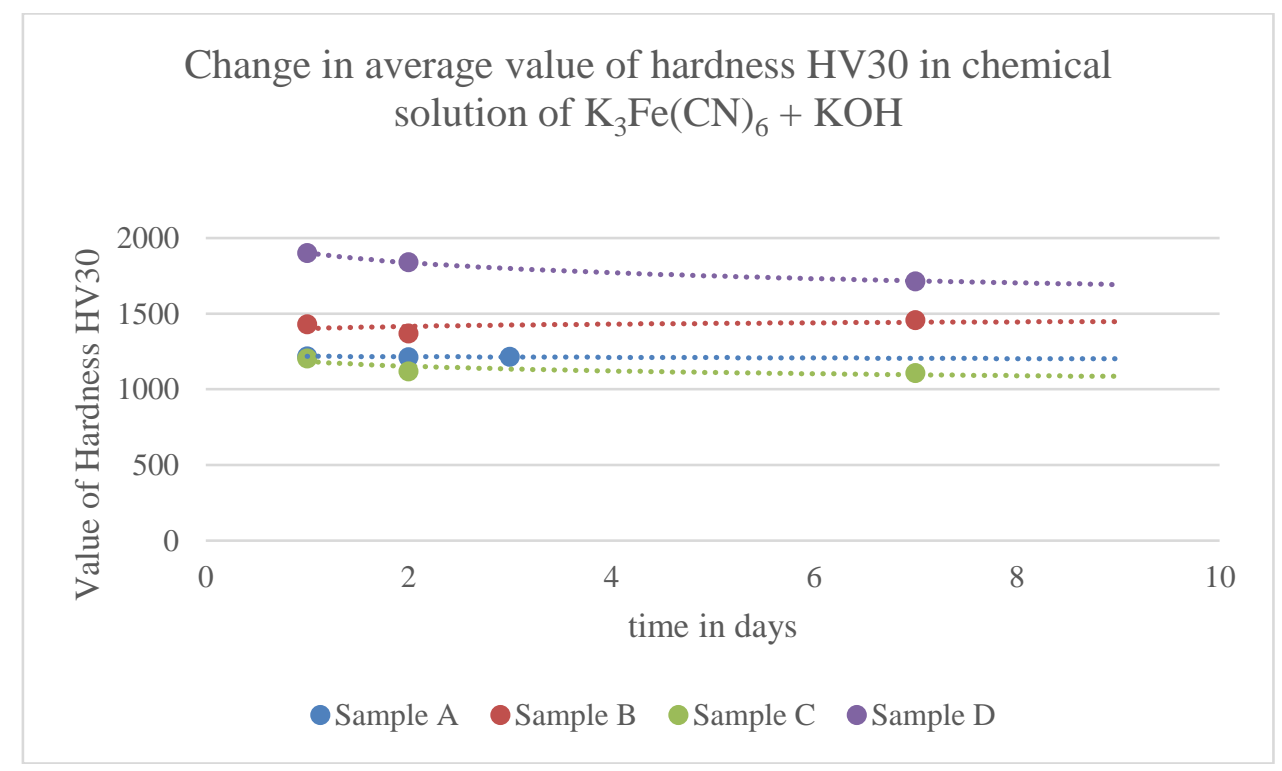

Fig. 6. Change in hardness of dissolved material in alkaline corrosive environments over time

It can be seen from Figure 6 that in the long-term exposure of the samples to the corrosive environment, the hardness of the samples gradually reduces. However, the rate at which this phenomenon occurs is constantly slowing down due to the formation of passivation layers on the surface of the analysed samples. In the sulphuric acid solution, there was a gradual loss of hardness throughout the experiment, see Fig 7.

The greatest decrease in the hardness of the surface layer was found in sample $\mathrm{D}$, both in the alkaline medium and in the acidic environment. In the alkaline medium, an average hardness loss of $10 \%$ was recorded for sample D. A hardness loss of $35 \%$ was recorded for sample $\mathrm{D}$ in the acidic solution.

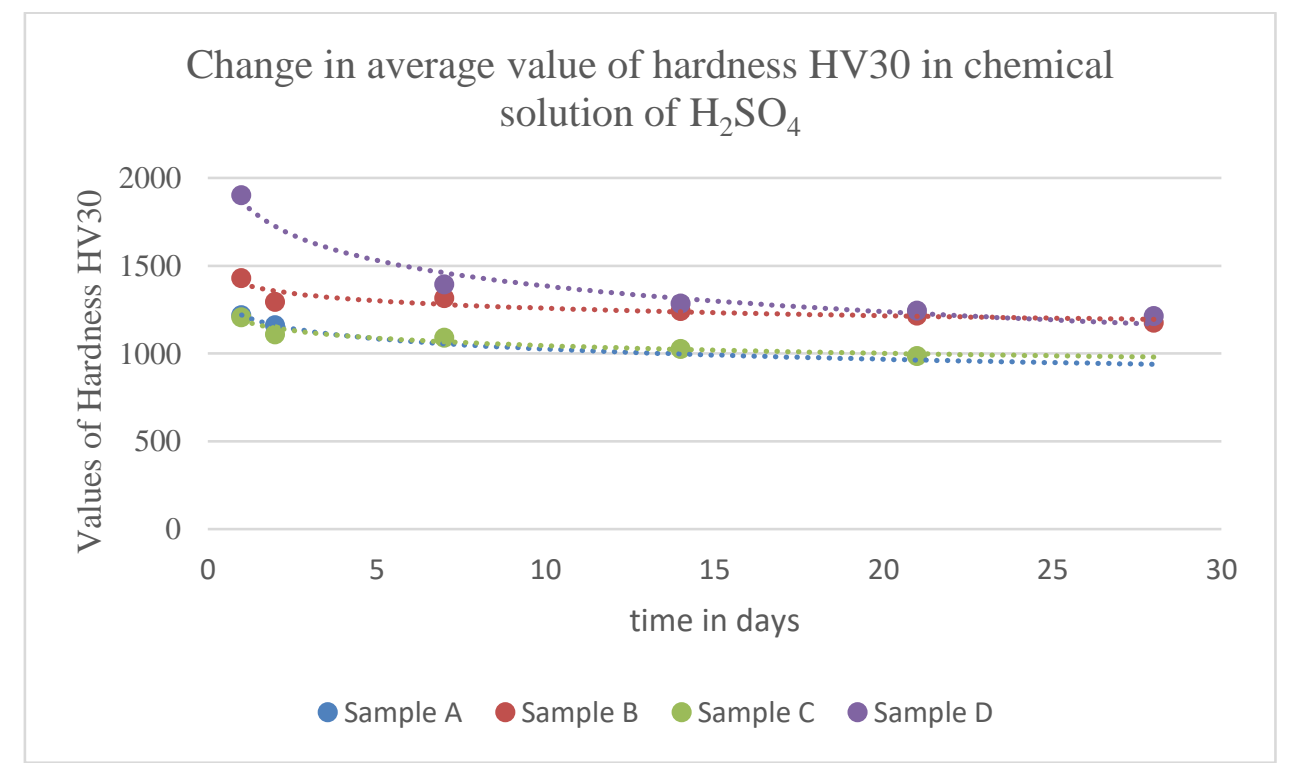

Fig. 7. Change in hardness of dissolved material in acidic corrosive environments over time

The rate of reduction of the hardness of the samples was again dependent on the size of the contact surface, the electrochemical properties of the corrosive environment and the chemical composition of the samples. These properties 
further affect the amount of binder dissolved in the corrosive environment. The amount of binder that was dissolved was determined for the environment which caused the highest degradation of the samples. This environment was sulphuric acid. The amount of binder dissolved was determined for samples A and D. These samples had different tungsten carbide grain size but the amount of binder was the same. Therefore it was possible to analyse the effect of grain size on the amount of the binder dissolved by sulphuric acid. Atomic absorption spectroscopy was used to analyse the weight of the dissolved binder in the sulphuric acid solution. Results of that analysis are summarized in Table 3. It can be seen that for the sample with finer tungsten carbide grains, sample D, a higher proportion of dissolved binder was observed than in the coarser sample - sample A. The amount of dissolved binder was about $16 \mathrm{wt} \%$ higher for the sample with the finer tungsten carbide grains.

\begin{tabular}{|c|c|c|}
\hline $\begin{array}{c}\text { Type of } \\
\text { Environment }\end{array}$ & Type of sample & $\begin{array}{c}\text { Amount of dissolved } \\
\text { binder (g) }\end{array}$ \\
\hline $\mathrm{H}_{2} \mathrm{SO}_{4}$ & Sample A & 0.145 \\
\hline $\mathrm{H}_{2} \mathrm{SO}_{4}$ & Sample D & 0.174 \\
\hline
\end{tabular}

Table 3. Amount of dissolved binder in the chemical solution

\section{Conclusion}

The aim of this research was to assess the corrosion resistance of different types of cemented carbides during longterm exposure in various types of corrosive environments. By analysing the weight of the samples after 32 days of exposure in the corrosive environments, it has been confirmed that nickel-based binders and alloyed binders have higher corrosion resistance in acidic environments than pure cobalt binders. The most intensive degradation of all types of sintered carbide samples occurred in the sulphuric acid and aqueous potassium ferricyanide solutions. In contrast, in aqueous solutions of $\mathrm{NaOH}, \mathrm{KOH}, \mathrm{CH}_{3} \mathrm{COOH}$, and $3 \mathrm{HCl}+\mathrm{HNO}_{3}$, the structures of all the samples did not dissolve as intensively. This was due to the formation of oxidic passivation layers, which, depending on the type of environment and the cemented carbide binder, slowed the further dissolution of the cemented carbide until it was completely stopped. This occurred in these environments during the first five days of the experiment.

A higher weight loss was observed for coarse grained sample A than for the fine-grained sample D in the solution of sulphuric acid and potassium ferric acid. This was observed during the first five days of exposure of the samples in corrosive environments. After this time, it was observed that the fine-grained samples began to dissolve more intensively. This can be explained by the fact that at the beginning of the dissolution of the cemented carbide structure, the finegrained cemented carbide, sample $\mathrm{D}$, has a higher corrosion resistance because of the high-temperature phase Co which evolved in the sample during the sintering process, in a larger volume than in the coarse-grained sample. However, finegrained cemented carbides consist of a higher number of corrosion elements that are formed at the interface of the carbide grains and the binder. These then cause a more intense dissolution of the cemented carbide than the coarse cemented carbide, where the number of these cells is lower. For this reason, the rate at which the sample structure dissolves changes over time. Thus, at the end of the experiment, a higher weight loss was observed for the fine-grained cemented carbide. This higher weight loss was reflected in the volume of binder dissolved in the corrosive environment. About 16 percent more binder of the fine-grained cemented carbide was dissolved in the sulphuric acid than for the coarse carbide. The volume of degraded material was then also reflected in a change in the mechanical properties of the cemented carbides. In the sulphuric acid environment, which degraded the cemented carbide structure the most intensively, there was a loss of hardness in samples of up to $35 \%$ in the case of the fine-grained sample D. For other samples, their different structures meant that the change in mechanical properties of hardness was not so pronounced and varied around $10 \%$.

Other experiments that build on the results of the experiments presented in this article will focus on studying changes in the electrochemical potential of corrosive environments after long term exposure of samples in these environments.

Also, we will study how other corrosive environments and methods of heat treatment affect the structure, mechanical properties, and corrosion resistance of cemented carbides.

\section{Acknowledgments}

This article was made possible by the funding for the SGS-2018-051 project "Application of new surface treatment and testing procedures for both surface and bulk materials in order to increase the applicability of a tool or tool in industrial practice".

\section{References}

[1] Bleicher, F., Finkeldei, D. and Siller, A. (2016). Machining of Difficult-To-Cut Materials. Proceedings of the 27th International DAAAM Symposium 2016, pp.0473-0479.

[2] Bozzini, B., Busson, B., De Gaudenzi, G., Humbert, C., Mele, C., Tedeschi, S. and Tadjeddine, A. (2016). Corrosion of cemented carbide grades in petrochemical slurries. Part I - Electrochemical adsorption of $\mathrm{CN}^{-}, \mathrm{SCN}^{-}$and $\mathrm{MBT}$ : A study based on in situ SFG. International Journal of Refractory Metals and Hard Materials, 60, pp.37-51. 
[3] Edtmaier, C., Schiesser, R., Meissl, C., Schubert, W., Bock, A., Schoen, A. and Zeiler, B. (2005). Selective removal of the cobalt binder in WC/Co based hardmetal scraps by acetic acid leaching. Hydrometallurgy, 76(1-2), pp.63-71.

[4] Federal carbide company: Corrosion Resistance of Tungsten Carbide Grades [online]. http://www.federalcarbide.com/corrosion_resistant_tungsten_carbide_grades.html. Accessed on: 2014-12-16

[5] Kellner, F., Hildebrand, H. and Virtanen, S. (2009). Effect of WC grain size on the corrosion behavior of WC-Co based hardmetals in alkaline solutions. International Journal of Refractory Metals and Hard Materials, 27(4), pp.806812.

[6] Kríž, A. and Bricín, D. (2017). Properties and Testing of Cemented Carbides. Powder Metallurgy - Fundamentals and Case Studies.

[7] Housecroft, C. and Sharpe, A. (2014). Anorganická chemie. Praha: Vysoká škola chemicko-technologická v Praze.

[8] Janeček J. (2015). Corrosion properties of sintered carbids. Master thesis. UWB in Pilsen. Faculty of Mechanical Engineering, Department of Material Science and Technology. Pilsen 2015.

[9] Konadu, D., Merwe, J., Potgieter, J., Potgieter-Vermaak, S. and Machio, C. (2010). The corrosion behaviour of WCVC-Co hardmetals in acidic media. Corrosion Science, 52(9), pp.3118-3125.

[10] Pomahač, J. (2016). Ecology of production and reclamation of cemented carbides. Bachelor thesis. UWB in Pilsen. Faculty of Mechanical Engineering, Department of Material Science and Technology. Pilsen 2015.

[11] Sarin, V. (2014). Comprehensive hard materials. Amsterdam: Elsevier

[12] Sutthiruangwong, S. and Mori, G. (2003). Corrosion properties of Co-based cemented carbides in acidic solutions. International Journal of Refractory Metals and Hard Materials, 21(3-4), pp.135-145.

[13] Špirit Z. (2013). Selected Properties and cutting tools applications of sintered caribides. Master thesis. UWB in Pilsen. Faculty of Mechanical Engineering, Department of Material Science and Technology. Pilsen 2013.

[14] Tang, W., Zhang, L., Chen, Y., Zhang, H. and Zhou, L. (2017). Corrosion and strength degradation behaviors of binderless WC material and WC-Co hardmetal in alkaline solution: A comparative investigation. International Journal of Refractory Metals and Hard Materials, 68, pp.1-8.

[15] Upadhyaya, G. (2003). Cemented tungsten carbides. Westwood, N.J: Noyes Publications. 